\title{
Carbide Precipitation in Ferrite in Nb-V-Bearing Low-Carbon Steel During Isothermal Quenching Process
}

\author{
Xiao-Lin $\mathrm{Li}^{1} \cdot$ Cheng-Shuai Lei $^{1} \cdot$ Xiang-Tao Deng $^{1} \cdot$ Yan-Mei Li $^{1} \cdot$ Yong Tian $^{1} \cdot$ Zhao-Dong Wang $^{1} \cdot$ \\ Guo-Dong Wang ${ }^{1}$
}

Received: 7 March 2017/Revised: 6 July 2017/Published online: 5 August 2017

(c) The Chinese Society for Metals and Springer-Verlag GmbH Germany 2017

\begin{abstract}
The precipitation behavior of nanometer-sized carbides in ferrite in $\mathrm{Nb}-\mathrm{V}$-bearing low-carbon steel was studied by electron microscopy and nanoindentation hardness measurements. The results indicated that interphase precipitation and random precipitation could occur simultaneously for the specimen isothermally treated at $700{ }^{\circ} \mathrm{C}$ for 60 min, while in other specimens, only random precipitation was observed. This phenomenon might be explained by mass balance criterion during the diffusional phase transformation. Nanohardness result indicated that the average hardness of the specimens isothermally held at $600{ }^{\circ} \mathrm{C}$ for $20 \mathrm{~min}$ was $3.87 \mathrm{GPa}$. For the specimen isothermally holding at $650{ }^{\circ} \mathrm{C}$ for $20 \mathrm{~min}$, the average hardness was $4.10 \mathrm{GPa}$ and the distribution of the nanohardness was in a narrower range compared with that of the specimen isothermal holding at $600{ }^{\circ} \mathrm{C}$ for $20 \mathrm{~min}$. These implied that the carbides in the specimens isothermal treated at $650{ }^{\circ} \mathrm{C}$ were more uniformly dispersed, and the number density of the carbides was greater than that treated at $600{ }^{\circ} \mathrm{C}$. Using Ashby-Orowan model, the contribution of precipitation strengthening to yield strength was estimated to be $\sim 110 \mathrm{MPa}$ for the specimen isothermally treated at the temperature of $650{ }^{\circ} \mathrm{C}$ for $20 \mathrm{~min}$.
\end{abstract}

\section{KEY WORDS: High-strength low-alloy (HSLA); Interphase precipitation; Carbides; Nanoindentation} hardness; High-resolution transmission electronic microscopy (HRTEM)

\section{Introduction}

In order to reduce costs in buildings, bridges, ships, and offshore platforms, a new generation of high-strength lowalloy (HSLA) steels strengthened by nanometer scale (Ti, Mo) $\mathrm{C}$ carbides was successfully launched on the market [1-3]. This state-of-the-art steel with nanosized precipitates and extremely soft matrix has attracted much attention

Available online at http://link.springer.com/journal/40195

Xiang-Tao Deng

dengxiangtao123@163.com

$\triangle$ Zhao-Dong Wang

zhdwang@mail.neu.edu.cn

1 State Key Laboratory of Rolling and Automation, Northeastern University, Shenyang 110819, China primarily. Increasing numbers of metallurgists have focused on designing manufacturing processes for forming nanometer scale precipitates in ferrite matrix [4-7].

It is well established that the precipitation of the carbides or carbonitrides in microalloyed steels containing one or more of the transition metals, such as $\mathrm{Nb}, \mathrm{Ti}$, and $\mathrm{V}$, plays a critical role in determining the properties of HSLA steels. During the last two decades, most of the investigations for the precipitation behavior have been concerned about $\mathrm{Nb}$, Ti, Ti-Mo, and Nb-Mo steels [8-10]. In contrast, for $\mathrm{Nb}-\mathrm{V}$ containing steels, the precipitation behavior has not been well understood. Interphase precipitation and random precipitation are two main precipitation morphologies. Interphase precipitation is believed to strengthen the matrix profoundly due to the tiny size and large quantity of the carbides. Since then, much effort has been focused on developing such precipitation morphology for various alloy carbides [10]. However, Chen et al. [11] 
suggested that random array carbides can achieve a better strengthening effect if they were distributed as finely as in interphase precipitation based on a mathematical modeling and computer simulation approach. Chen et al. [12] examined a Ti-V-microalloyed steel and found that interphase precipitation and random precipitation occurred simultaneously in the same ferrite grain.

Thus, the purpose of the present study is to elucidate the precipitation behavior of carbides in $\mathrm{Nb}-\mathrm{V}$-microalloyed steel after isothermal quenching, including morphology, size distribution, and crystallography of the precipitates. Furthermore, the contribution of precipitation strengthening to yield strength was theoretically estimated using empirical equations.

\section{Materials and Experimental Procedure}

The nominal chemical composition of the experimental steel was Fe-0.09C-1.05Mn-0.25Si-0.03V-0.025Nb$0.011 \mathrm{Ti}$. The alloy was prepared by vacuum melting and cast into ingot of thickness $\sim 100 \mathrm{~mm}$. The ingot was homogenized at $1200{ }^{\circ} \mathrm{C}$ for $1 \mathrm{~h}$ and then hot-rolled into steel plate of $12 \mathrm{~mm}$ thickness via seven passes on the $\Phi 450 \mathrm{~mm}$ trial rolling mill. The heat treatment was carried out using a Formastor-FII dilatometer at a vacuum of $10^{-5}$ Torr to prevent oxidation. Prior to the preparation of dilatometer specimens, small specimens cut from the steel plates were homogenized at $1200{ }^{\circ} \mathrm{C}$ for 3 days in evacuated quartz capsules, followed by water quenching. The specimens were prepared from the mid-thickness of steel plates along the rolling direction and machined into 3-mmdiameter cylindrical rods of $10 \mathrm{~mm}$ length. A schematic diagram of isothermal heat treatment process is shown in Fig. 1. The specimens were heated at a rate of $10{ }^{\circ} \mathrm{C} / \mathrm{s}$ from room temperature to $1200{ }^{\circ} \mathrm{C}$ and kept at this temperature

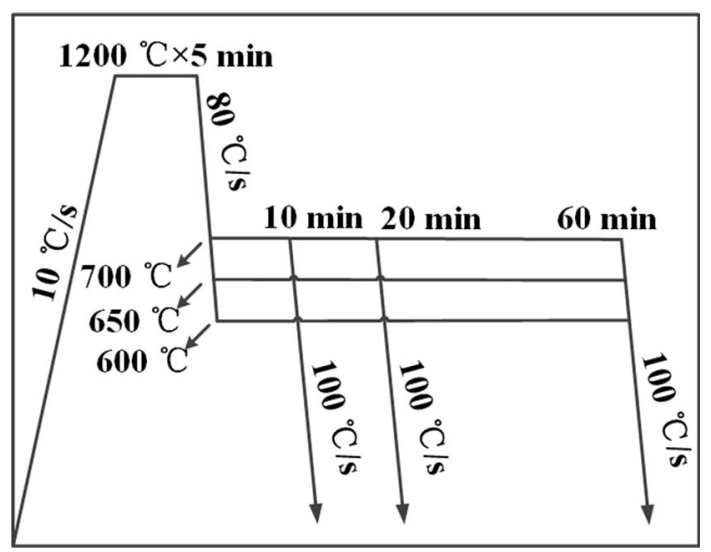

Fig. 1 Schematic diagram of isothermal heat treatment process for $5 \mathrm{~min}$ to dissolve all the carbides. After austenitizing at $1200{ }^{\circ} \mathrm{C}$, the specimens were directly cooled to 600,650 , and $700{ }^{\circ} \mathrm{C}$ at a cooling rate of $80{ }^{\circ} \mathrm{C} / \mathrm{s}$ and kept at these temperatures for 10, 20, and $60 \mathrm{~min}$, respectively. Finally, they were cooled to room temperature at a cooling rate of $100{ }^{\circ} \mathrm{C} / \mathrm{s}$ using $\mathrm{He}$ gas.

The specimens for optical metallography were prepared from dilatometer specimens and were mechanically polished to mirror finish and etched with 4 vol\% nital solution at room temperature. Ferrite grain size was measured by linear intercept method, and the volume fraction of the ferrite was determined by point counting method via Image-Pro Plus. TEM specimens were produced by cutting slices from the dilatometer specimens, thinning them mechanically to $0.06 \mathrm{~mm}$, and electrolytically jet polished in a solution of $9 \mathrm{vol} \%$ perchloric acid in ethanol at $-25{ }^{\circ} \mathrm{C}$. TEM experiments were carried out using an FEI Tecnai $\mathrm{G}^{2}$ F20 microscope operating at $200 \mathrm{kV}$ to characterize morphology, size distribution, and crystallography of the precipitates. To determine the volume fraction of the carbides, the specimen thickness was measured by counting the number of thickness fringes near the electropolished hole of thin foils, produced under two-beam condition [13].

To study the impact on precipitation hardening, nanoindentation hardness measurements were taken for the corresponding samples with Berkovich indenter.

\section{Results and Discussion}

\subsection{Microstructural Characterization}

In order to characterize isothermal phase transformation in the experimental steel, the optical microstructures of the steel at different isothermal aging temperatures were first investigated. Figure 2 shows the optical microstructures for different aging times at various aging temperatures. The specimens had a two-phase microstructure. The whiteetched phases were polygonal ferrites, nucleating and growing during isothermal transformation, and the darketched phases were martensites obtained during rapid cooling of untransformed austenite. Figure $2 \mathrm{~d}-\mathrm{f}$ presents optical micrographs of the specimens isothermally held at $650{ }^{\circ} \mathrm{C}$ for 10,20 , and $60 \mathrm{~min}$, respectively. It may be noted that the volume fraction and the grain size of the ferrite increased with aging time, as shown in Fig. 2k. Figure 2a, d, g shows optical micrographs of the specimens isothermally treated at 600,650 , and $700{ }^{\circ} \mathrm{C}$ for $10 \mathrm{~min}$, respectively. The volume fraction of ferrite phase decreased with increased isothermal temperature, which is related to the equilibrium content of ferrite fraction at various temperatures. On the other hand, the ferrite grain 

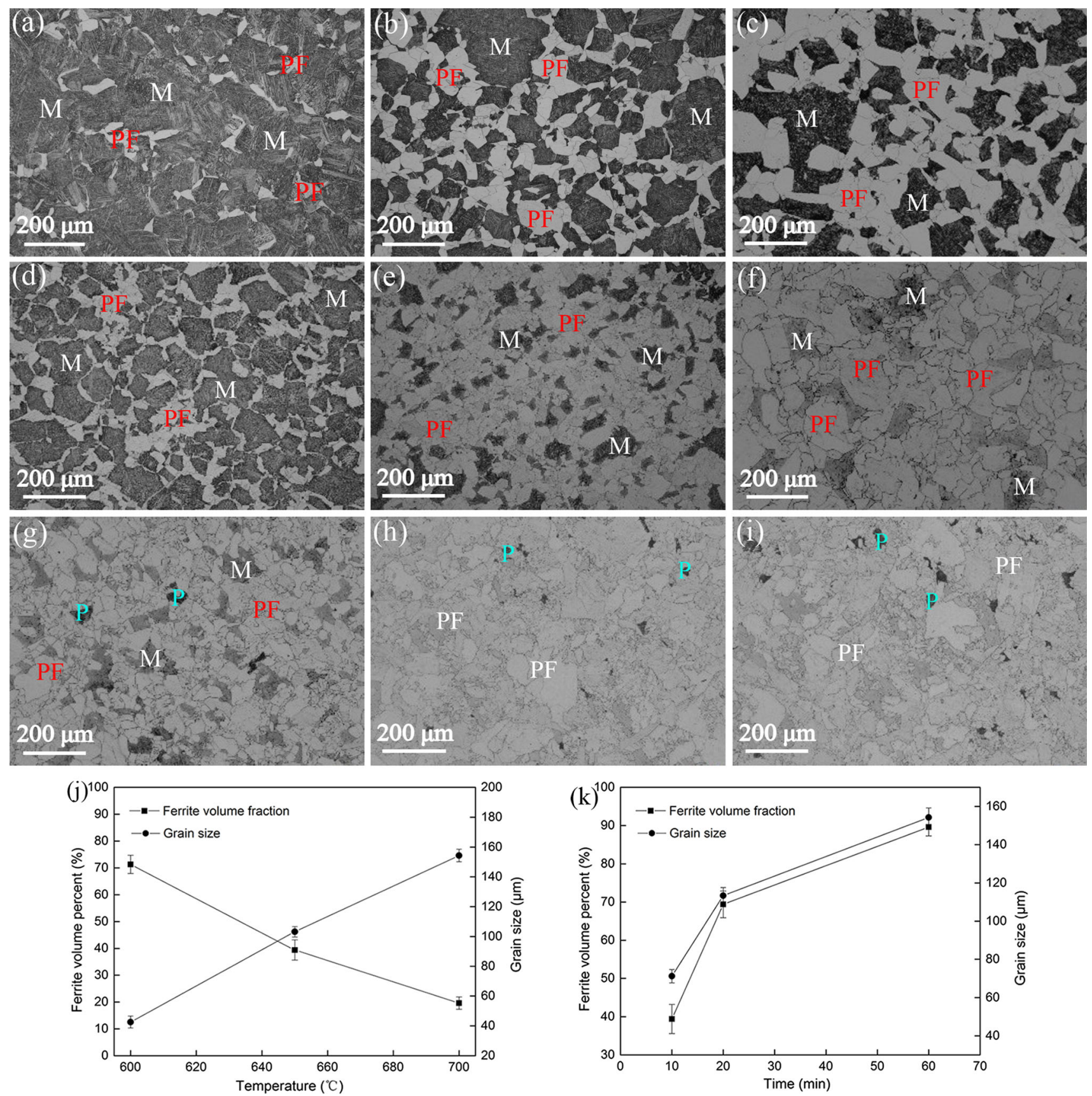

Fig. 2 Optical micrographs obtained from dilatometer specimens isothermal holding at a-c $700{ }^{\circ} \mathrm{C}, \mathbf{d}-\mathbf{f} 650{ }^{\circ} \mathrm{C}$, and $\mathbf{g}-\mathbf{i} 600{ }^{\circ} \mathrm{C}$ for 10,20 , and $60 \mathrm{~min}$, respectively; with plots in displaying variation in the ferrite volume fraction and the grain size versus $\mathbf{g}$ isothermal temperature for $10 \mathrm{~min}, \mathbf{k}$ isothermal time at $650{ }^{\circ} \mathrm{C}$

size increased with rising the isothermal temperature because of low nucleation rate (less undercooling) at high temperature, as shown in Fig. 2j. Figure 2g-i illustrates the microstructures of the specimen isothermally treated at $600{ }^{\circ} \mathrm{C}$ for different times, it can be noted that beside ferrite and martensite, pearlite was also observed, and the fraction of the pearlite increased with isothermal holding times. The microstructural evolution can be explained by the TTT diagram simulated by JMatpro presented in Fig. 3a. Figure $3 \mathrm{~b}$ shows the phase diagram simulated by Thermo-calc software, which illustrates the phase fraction versus temperature. It is evident that three kinds of the precipitates can be obtained, TiN, NbC, and VC. Their corresponding precipitation starting temperatures are 1081, 855 , and $807{ }^{\circ} \mathrm{C}$. The detailed compositions of these phases with temperature are shown in Fig. 3c-e. 

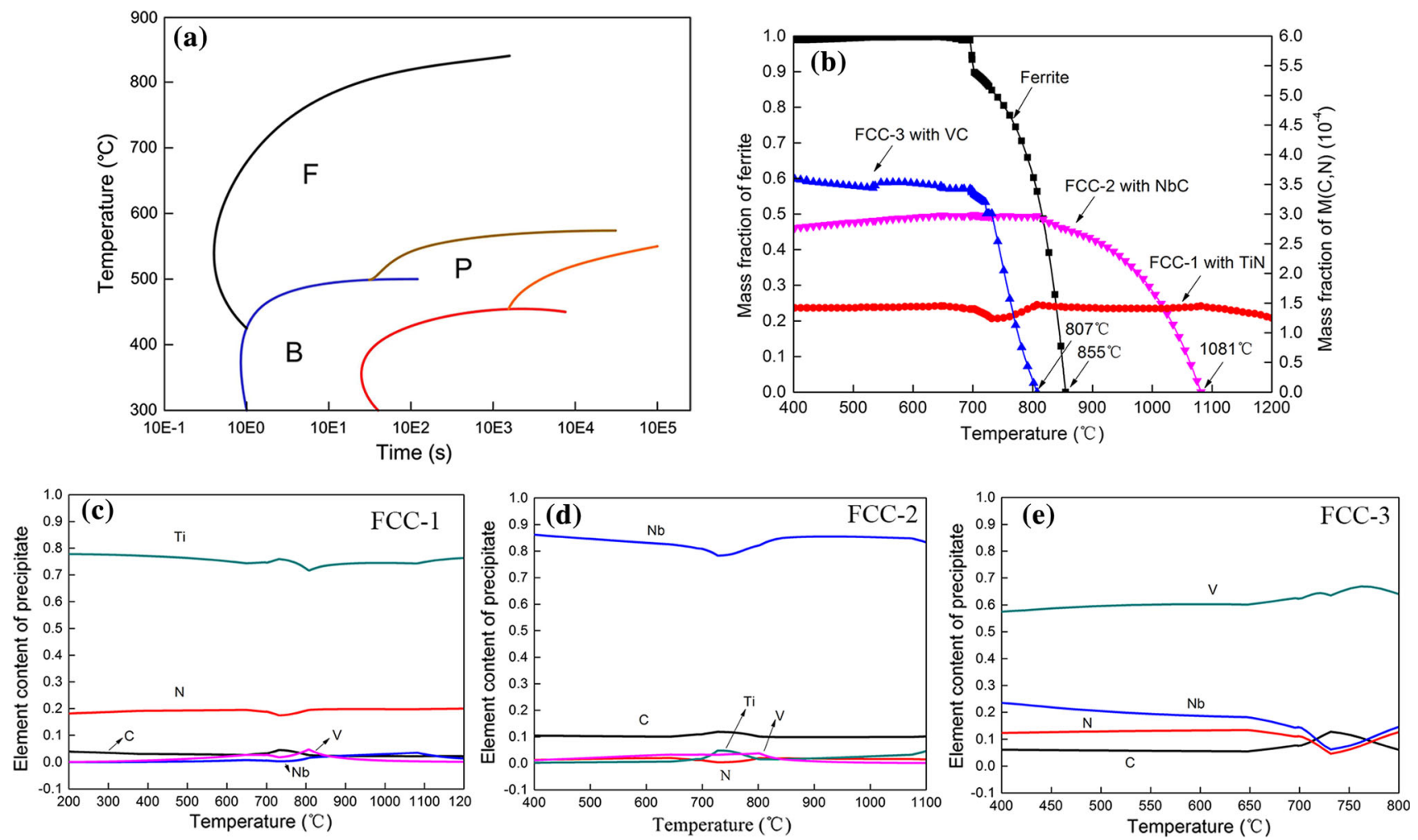

Fig. 3 a TTT curves of experimental steel simulated by JMatpro simulation, relationship of precipitated phase b corresponding composition of these phases $\mathbf{c}-\mathbf{e}$ with temperatures

\subsection{Precipitation Behavior}

TEM studies were carried out to characterize the precipitate morphology, distribution, orientation relationship, and lattice parameter. They were classified into two types of sizes. The first type of the precipitates was in the size range of 30-200 nm, including cuboid-shaped TiN (Fig. 4a, b), and spherical or elliptical (Ti, Nb)CN (Fig. 4c). Figure $4 \mathrm{~d}$, e shows the corresponding EDS of the particle shown in Fig. 4b, c, respectively. It is known that precipitation of TiN occurs in two temperature regimes, including solidification process, and in supersaturated austenite after solidification. ( $\mathrm{Ti}, \mathrm{Nb}) \mathrm{CN}$ with the size range similar to TiN was thermodynamically stable in austenite and ferrite and was not dissolved during hot rolling. TiN and (Ti, $\mathrm{Nb}) \mathrm{CN}$ precipitates at high temperatures are expected to pin the austenite grain boundaries, thereby inhibiting recrystallization and grain growth during hot rolling. This led to refinement of final ferrite grain size [14].

The second type of the precipitates interested in this study was nanoscale dimensions primarily formed during the austenite to ferrite transformation process or in supersaturated ferrite. The size of these precipitates was less than $10 \mathrm{~nm}$, containing $\mathrm{Nb}$ and $\mathrm{V}$. These carbides can be classified into two categories, including interphase precipitation carbides and supersaturated spherical carbides.
The row-like characteristic of interphase precipitation cannot be observed under TEM unless the specimen is tilted such that the incident electron beam direction is parallel to the plane on which the carbides are precipitated $[10,15]$. Figure 5 illustrates the schematic of the approach to observe interphase precipitation carbides via TEM. Assuming the precipitation of the carbides on an interface parallel to the $(h, k, l)_{\alpha}$ of the ferrite grain, which is well known as the sheet plane, the direction of the incident electron beam $[u, v, w]_{\alpha}$ must satisfy the zone equation: $h u+k v+l w=0$. If not, the interphase precipitation will be observed as randomly distributed precipitates. Figure 6 shows the precipitation morphologies of the specimen isothermally holding at $700{ }^{\circ} \mathrm{C}$ for $60 \mathrm{~min}$. Both interphase precipitates and supersaturated spherical carbides can be observed, but interphase precipitation occurred only in three ferrite grains among the observed total number of 30 .

A series of zone axis were selected for the specimen isothermally treated at $700{ }^{\circ} \mathrm{C}$ for $60 \mathrm{~min}$. In Fig. $6 \mathrm{a}$, the row-like interphase precipitation is shown. It was found that the precipitation was oriented close to $(013)_{\alpha}$ under zone axes $[100]_{\alpha}$, which satisfied the zone equation as $1 \times 0+0 \times 1+0 \times 3=0$. The row spacing $(s)$ in interphase precipitation of the carbides was $(19 \pm 4) \mathrm{nm}$. The mean projected value of the intercarbide spacing in sheet $\left(\omega_{0}\right)$ was $3.2 \mathrm{~nm}$. And the average intercarbide 

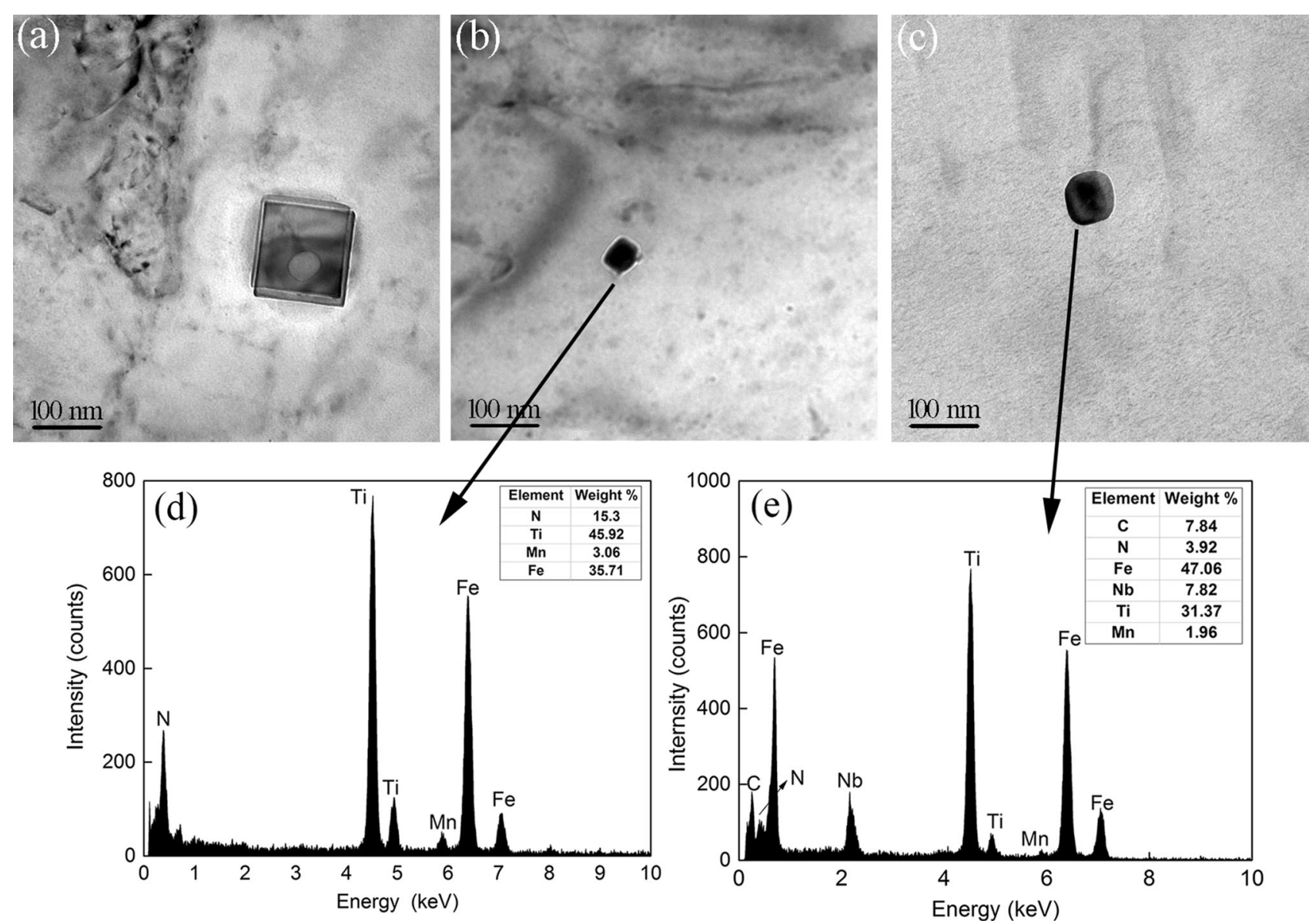

Fig. 4 TEM micrographs showing precipitates with cuboid shape $\mathbf{a}, \mathbf{b}, \mathbf{c}$ spherical shape; the corresponding EDS of precipitate $\mathbf{d}, \mathbf{e}$ in $\mathbf{b}$, $\mathbf{c}$, respectively

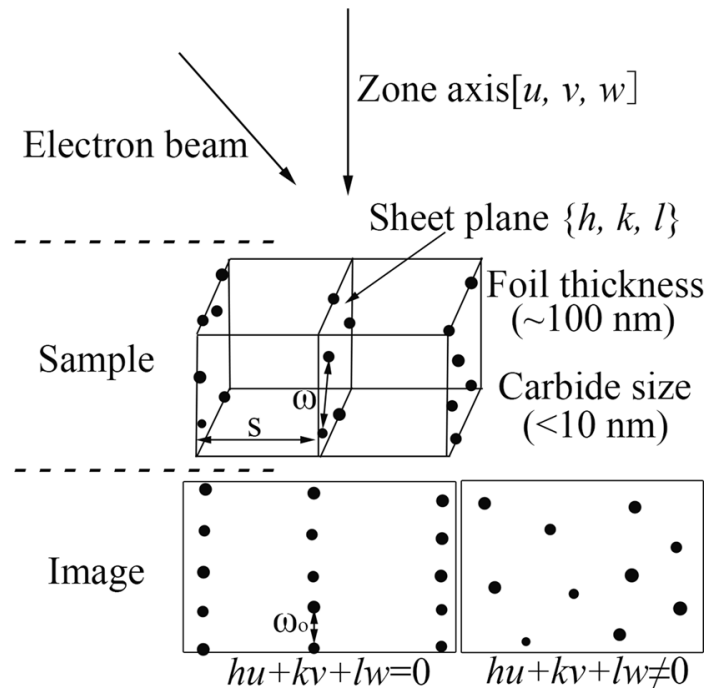

Fig. 5 Schematic of TEM observation about the interphase precipitation carbides ( $s$ is the perpendicular sheet spacing; $\omega$ is the average intercarbide spacing in the sheet plane; $\omega_{0}$ is the mean projected value of the intercarbide spacing in sheet) spacing in the sheet plane $(\omega)$ was calculated to be $48 \mathrm{~nm}$. Another approach was tilting the specimen as follows. If the zone axis is transferred from $[100]_{\alpha}$ to $[210]_{\alpha}$, which does not satisfy the zone equation, the interphase precipitation of the carbides as rows could not be observed as shown in Fig. 6b. This zone axis was not appropriate to observe interphase precipitation carbides. It is worth noting that there were several other preferred sheet planes around $(013)_{\alpha}[16]$. The results clearly indicate that the development of incoherent $\gamma / \alpha$ interface has the advantage over the semi-coherent $\gamma / \alpha$ interface for interphase precipitation. Batte and Honeycombe [17] presented a similar result showing that the sheet planes are not oriented on $\{110\}_{\alpha}$ in Fe-V-C alloys. A recent study by Yen et al. [18] also suggested that there were several preferred sheet planes oriented at $\{211\}_{\alpha}$ and $\{111\}_{\alpha}$. The discrepancy between TEM results and general proposition by Batte and Honeycombe was explained by Yen et al. [18] via three models. It was pointed that the incoherent interface movement is associated with the ledge mechanism. The interphase 

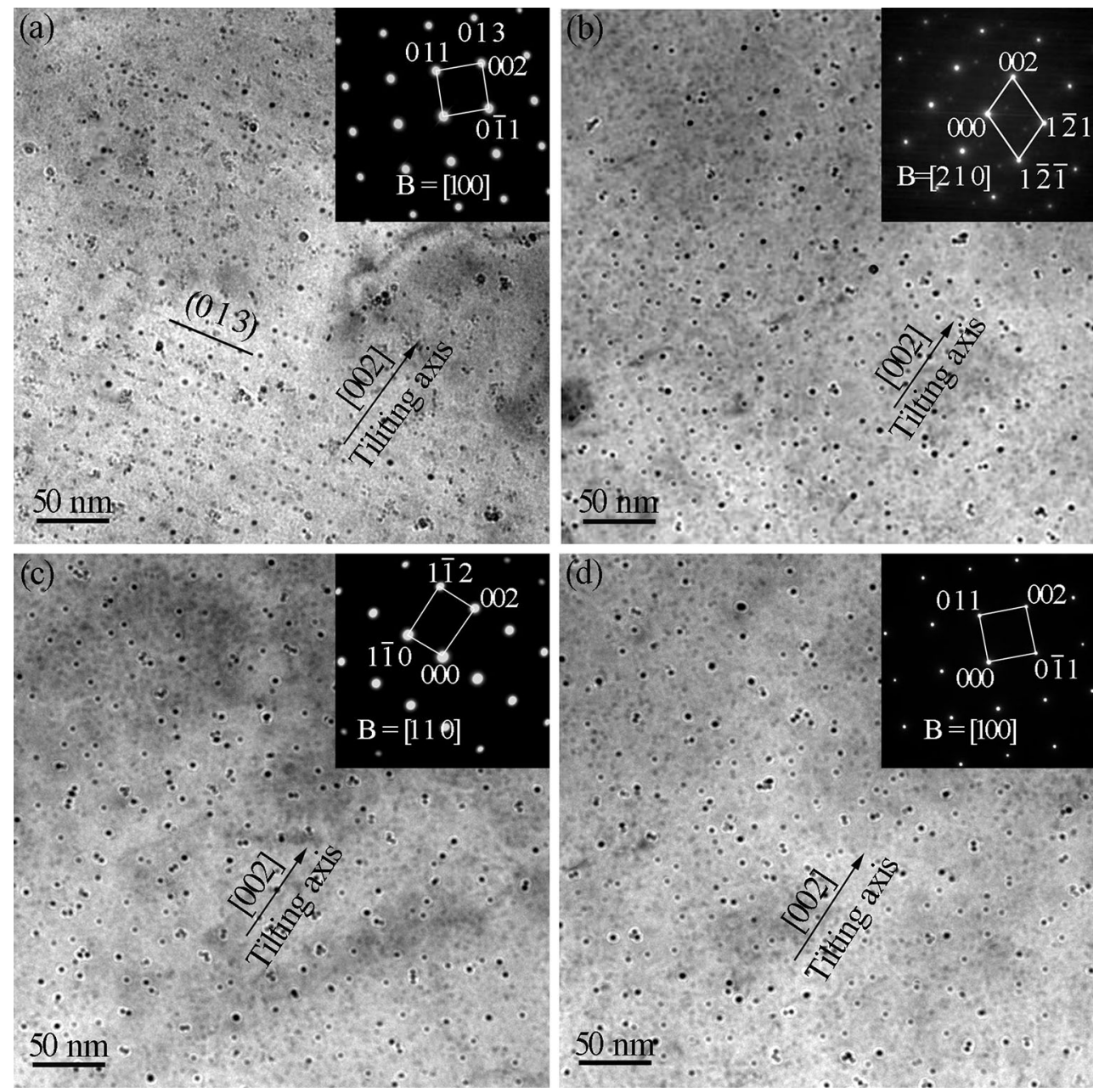

Fig. 6 a Morphology of row-like sheet plane of the interphase precipitation and the inset is the corresponding diffraction pattern of the ferrite with the zone axis $[100]_{\alpha} ; \mathbf{b}$ the morphology of the random dispersion of carbides obtained by tilting the TEM thin foil to the zone axis [210] $]_{\alpha}$ and the inset is the corresponding SADP; the random distribution carbides with the zone axis of $[110]_{\alpha}$ and $[100]_{\alpha}$ in the specimen isothermally treated at $700{ }^{\circ} \mathrm{C}$ for $60 \mathrm{~min}$

precipitation occurs on the incoherent interface via lateral ledge growth of the ferrite, and these incoherent interfaces must have relatively low-energy terrace planes on which the carbides can nucleate. Okamoto et al. [19] proposed that the choice of the precipitation plane depends on the orientation of the ferrite grains relative to the austenite matrix, and there seems to be a competition between different orientations.

In Fig. 6c, the randomly distributed precipitates in the specimen isothermally treated at $700{ }^{\circ} \mathrm{C}$ for $60 \mathrm{~min}$ were observed using zone axis $[110]_{\alpha}$. Thereafter, several ways of tilting the TEM specimens were attempted. When the zone axis of ferrite matrix is transferred from $[110]_{\alpha}$ to $[100]_{\alpha}$, as shown in Fig. 6d, only random distributed precipitates can be observed during the tilting process. Thus, we conclude that both interphase and random precipitates were obtained at isothermal temperature of $700{ }^{\circ} \mathrm{C}$ for $60 \mathrm{~min}$.
Figure 7 shows the TEM micrographs of the precipitates along the $[100]_{\alpha}$ zone axis in the specimens isothermally held at 600,650 , and $700{ }^{\circ} \mathrm{C}$ for $10 \mathrm{~min}$. In these specimens, only random dispersion of carbides was observed in zone axis of $[100]_{\alpha}$. Thereafter, several ways of tilting the TEM specimens were attempted, but no interphase precipitation carbides were observed.

According to the previous studies, the interphase precipitation occurs at relatively higher temperatures, and it was also observed that interphase precipitation can only occur in some ferrite grains, not in all [20-22]. In our study, interphase precipitation was observed only in some ferrite grains when the specimen was isothermally holding at the temperature of $700{ }^{\circ} \mathrm{C}$ for $60 \mathrm{~min}$. It is generally agreed that the ledge velocity is inversely proportional to the isothermal aging temperature [23]. At higher isothermal temperature, driving force for $\gamma / \alpha$ transformation and ledge migration velocity reduce, and the possibility of interphase 

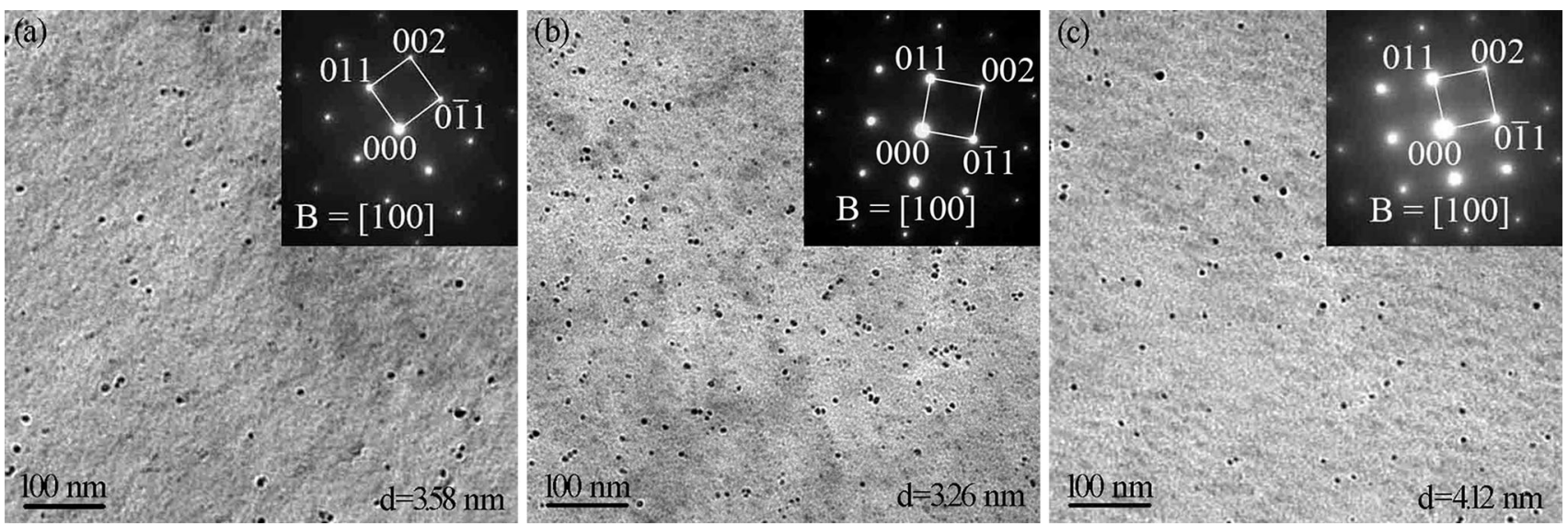

Fig. 7 Morphology of random distributed nanometer-sized carbides in the zone axes of [100] $]_{\alpha}$ in specimens isothermally treated at a 600 , b 650 , c $700{ }^{\circ} \mathrm{C}$ for $10 \mathrm{~min}$

precipitation formation increases. The majority of the ferrite would form in a very short time and lead to higher ledge mobility. When the mobility of the ledge is too fast, the interface precipitation of the carbides cannot nucleate and grow, such that the microalloying elements are in the ferrite matrix. Since the solubility of these microalloyed carbides in the ferrite is at least an order of magnitude smaller than in the austenite, these supersaturated microalloying elements will precipitate during the isothermal process. Figure 8 shows the schematic diagram about the formation of interphase precipitation in polygonal ferrite by ledge migration. It is well known that the polygonal ferrite must follow the mass balance criterion during the diffusional phase transformation, as shown in Eq. (1) [24].

$V_{\text {coh }} \times L_{1}=V_{\text {ledge }} \times L_{2}$,

where $V_{\text {coh }}$ and $V_{\text {ledge }}$ are the $\gamma / \alpha$ boundary moving velocity and the ledge migration velocity, respectively. $L_{1}$ and $L_{2}$ are inter-ledge spacing and ledge spacing, respectively.

The growth of the ferrite into the austenite is controlled by carbon atom diffusion driven by the carbon gradient ahead of $\gamma / \alpha$ boundary, maintaining local equilibrium or paraequilibrium in the interphase. Polygonal ferrite growth mechanism could be described as Eqs. (2)-(4), assuming

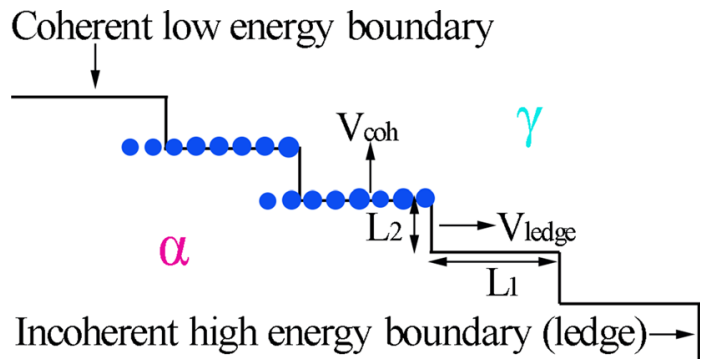

Fig. 8 Schematic diagram shows formation of interphase precipitation thickening of polygonal ferrite by ledge migration that the $\gamma / \alpha$ interface as a planar front grows into austenite [25].

$$
\begin{aligned}
X= & \frac{\left(C_{\mathrm{c}}^{\gamma / \alpha}-C_{\mathrm{c}}^{\gamma / \infty}\right)^{2}}{\sqrt{\left(C_{\mathrm{c}}^{\gamma / \alpha}-C_{\mathrm{c}}^{\alpha}\right)\left(C_{\mathrm{c}}^{\gamma / \infty}-C_{\mathrm{c}}^{\alpha}\right)}} \times \sqrt{D_{\mathrm{c}}^{\gamma} t}, \\
V_{\mathrm{coh}}= & \frac{\mathrm{d} x}{\mathrm{~d} t}=\frac{1}{2} \times \frac{\left(C_{\mathrm{c}}^{\gamma / \alpha}-C_{\mathrm{c}}^{\gamma / \infty}\right)}{\sqrt{\left(C_{\mathrm{c}}^{\gamma / \alpha}-C_{\mathrm{c}}^{\alpha}\right)\left(C_{\mathrm{c}}^{\gamma / \infty}-C_{\mathrm{c}}^{\alpha}\right)}} \times \sqrt{\frac{D_{\mathrm{c}}^{\gamma}}{t}} \\
V_{\text {ledge }}= & V_{\mathrm{coh}} \times\left(\frac{L_{1}}{L_{2}}\right) \\
= & \frac{1}{2} \times \frac{\left(C_{\mathrm{c}}^{\gamma / \alpha}-C_{\mathrm{c}}^{\gamma / \infty}\right)}{\sqrt{\left(C_{\mathrm{c}}^{\gamma / \alpha}-C_{\mathrm{c}}^{\alpha}\right)\left(C_{\mathrm{c}}^{\gamma / \infty}-C_{\mathrm{c}}^{\alpha}\right)}} \times \sqrt{\frac{D_{\mathrm{c}}^{\gamma}}{t}} \\
& \times\left(\frac{L_{1}}{L_{2}}\right),
\end{aligned}
$$

where $X$ is the distance from the point of the ferrite nucleation to the location of the $\gamma / \alpha$ boundary at time. $D_{c}^{\gamma}$ is the diffusion coefficient of carbon in the austenite. $C_{c}^{\gamma / \alpha}$, $C_{c}^{\gamma / \infty}$, and $C_{c}^{\alpha}$ display the carbon content of the austenite at the $\gamma / \alpha$ interface, the original carbon content of the austenite, and the carbon content of the ferrite in equilibrium with the austenite.

From Eq. (4), it may be noted that high ledge migration velocity would be obtained in the early stage of transformation; then, the interphase precipitation cannot nucleate and grow in the short time of transformation. When it comes to the end of transformation, the ledge migration rate becomes slower and will be facilitate interphase precipitation. Therefore, interphase precipitation just nucleated in the specimens isothermally treated at high temperature and long time. 
For precipitation strengthening of random precipitates, the size and volume fraction are two main factors considered. In this study, HRTEM image of nanometer-sized carbide was used to measure the precipitate size, as shown in Fig. 9a. The carbides were very fine and within the thickness of foil. This led to the development of Moiré fringe contrast because overlapping carbide and ferrite lattices which provided a clear contrast of carbides used for accurate measurement of carbide size. The size of carbides in Fig. 9a was determined to be $4.32 \mathrm{~nm}$ along the direction of the Moiré fringe (length) and $4.16 \mathrm{~nm}$ perpendicular to the direction of the Moiré fringe (thickness). The aspect ratio (length/thickness) was close to 1 . It can be concluded that the morphology of carbide was nearly spherical. The average value of length and thickness of carbide was $\sim 4.24 \mathrm{~nm}$. The volume fraction $f_{v}$ of randomly distributed carbides was estimated from the following equation:

$f_{v}=\frac{\frac{4}{3} \pi\left(\bar{R}_{\mathrm{v}}\right)^{3} \cdot n}{V}=\frac{2}{3} d \cdot \frac{f_{\mathrm{s}}}{h}$,

where $\bar{R}_{\mathrm{V}}$ is the average radius of the precipitates, $n$ is the number of the precipitates in a TEM image, $V$ is the volume fraction of the TEM foil specimens, $d$ is the diameter of the precipitates, $f_{\mathrm{s}}$ is the area percentage of the precipitates in the TEM image, and $h$ is the thickness of TEM specimen. The plot of carbide size and number density as a function of isothermal holding temperature is presented in Fig. 9b, which clearly indicates that the carbide was fine and dense at $650{ }^{\circ} \mathrm{C}$ compared to that at 600 and $700{ }^{\circ} \mathrm{C}$. We can conclude that $650{ }^{\circ} \mathrm{C}$ was closest to the nose of precipitation-time-temperature (PTT) curve. It is well recognized that the number density is controlled by thermodynamic driving force and kinetics of diffusion of microalloying elements. At $650{ }^{\circ} \mathrm{C}$, the thermodynamics and kinetics were optimum for carbide precipitation. In addition, the volume fraction of the random distributed precipitates in the specimens isothermally treated at 600 , 650 , and $700{ }^{\circ} \mathrm{C}$ can be calculated to be $0.0127,0.0207$, and $0.0267 \%$, respectively.

In addition, TEM studies were conducted at different holding time at $650{ }^{\circ} \mathrm{C}$ to study coarsening of the precipitates. Figure 10 shows carbide morphology and distribution for the specimens isothermal treated at 600 and $650{ }^{\circ} \mathrm{C}$ for 10,20 , and $60 \mathrm{~min}$. At all the isothermal holding times, only random precipitates were observed. The average diameters of the carbides in Fig. 10a-c were determined to be $\sim 3.26, \sim 4.15$, and $\sim 6.29 \mathrm{~nm}$, as shown in the histogram in Fig. 11. The average size data were obtained from 30 carbides and at least three polygonal ferrite grains. At all holding times, the carbide size was determined to be $\sim 2-15 \mathrm{~nm}$. This is in good agreement with the previous atom probe or neutron scattering results [26-28], indicating that the average size obtained by Moiré fringe in HRTEM image is reasonably accurate. In addition, the volume fractions of the precipitates were determined to be $\sim 0.0207,0.0483$, and $0.0917 \%$, respectively. Figure 10d shows the carbide morphology in the specimen isothermally treated at $600{ }^{\circ} \mathrm{C}$ for $20 \mathrm{~min}$. The carbide was finer and more uniform than that in $650{ }^{\circ} \mathrm{C}$ for the same time.

Although TEM is a very direct and powerful tool for analyzing nanosized precipitates, it is exhausting to make

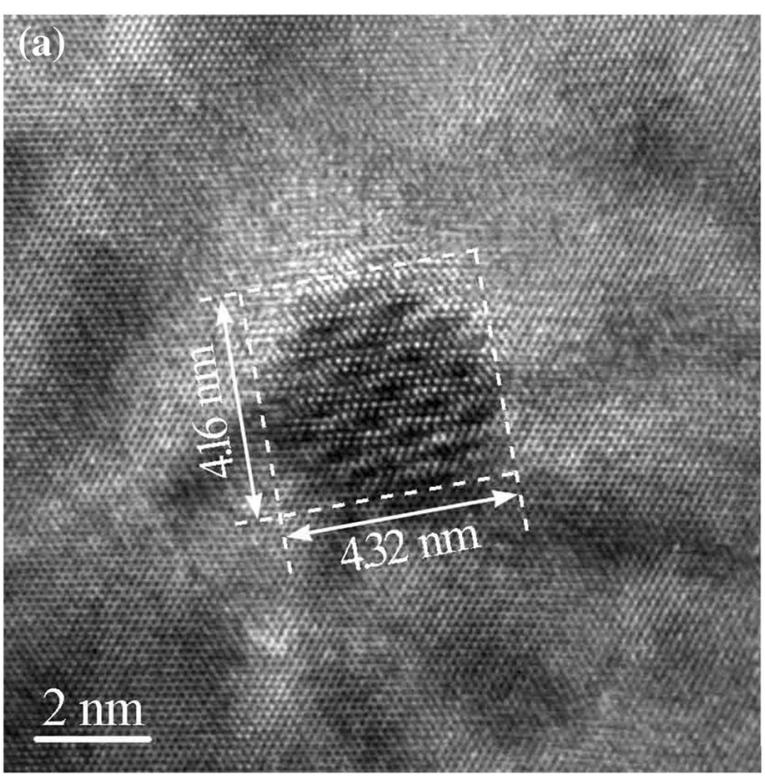

(b)

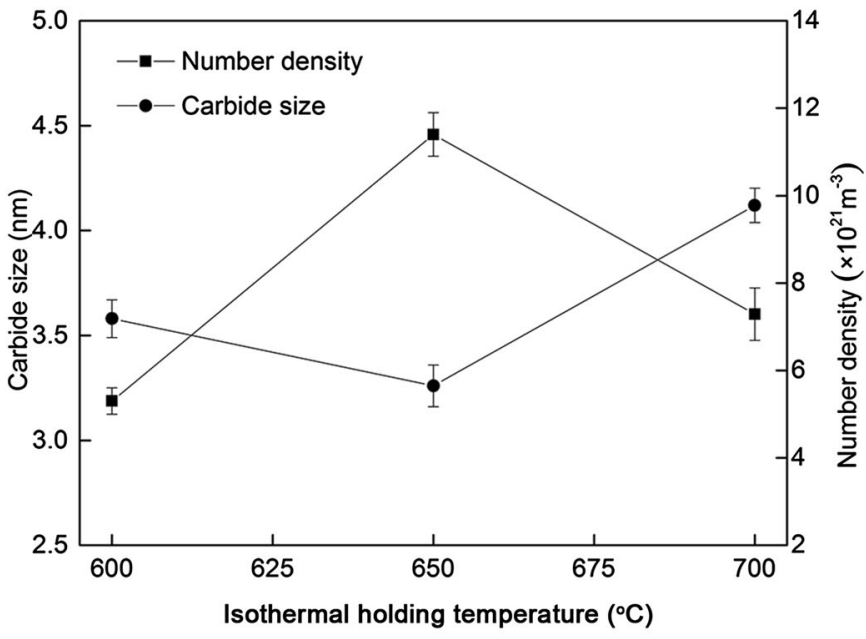

Fig. 9 a Representative HRTEM micrograph of nanometer-sized carbide and $\mathbf{b}$ plots showing average size and number density of the carbides as a function of isothermal holding temperature 

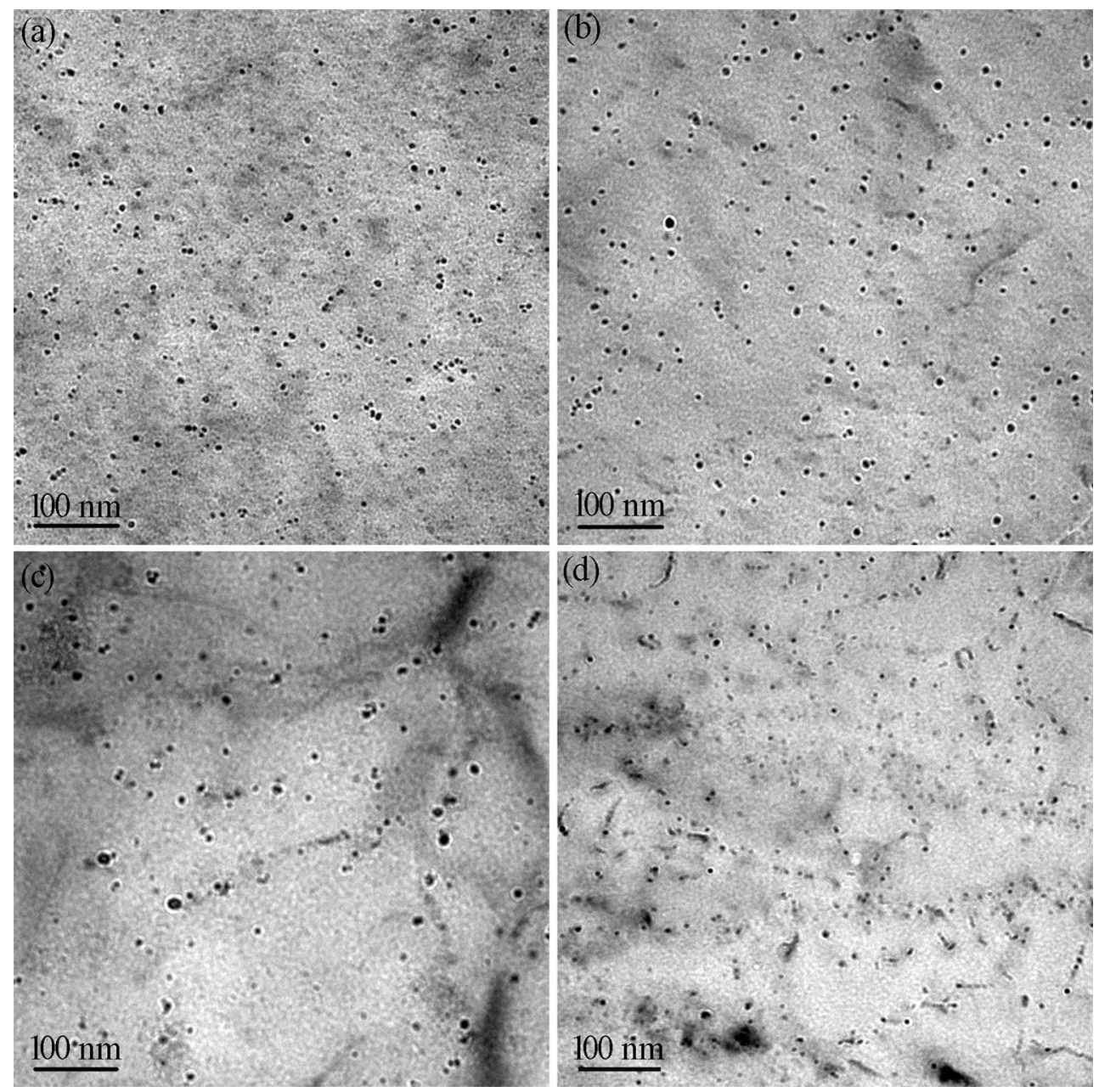

Fig. 10 TEM micrographs of the specimen isothermally treated at $650{ }^{\circ} \mathrm{C}$ for a 10 , b 20 , c 60 min at d $600{ }^{\circ} \mathrm{C}$ for 20 min

numerous TEM thin foils to observe nanometer scale particles. The nanoindenter hardness test approach provides researchers a convenient and fast way to evaluate the precipitation status of ferrite grain. Figure 12 shows the typical indentation morphology, where the indents were placed $5 \mu \mathrm{m}$ apart. The elastic load-depth plots calculated by Hertzian elastic contact solution [29] gave that the reduced modulus was $215 \mathrm{GPa}$. Figure $12 \mathrm{~b}$, c shows the histogram of the hardness distribution in polygonal ferrite grains in specimens isothermally treated at 600 and $650{ }^{\circ} \mathrm{C}$ for $20 \mathrm{~min}$, from which the average nanohardness was measured to be 3.87 and $4.10 \mathrm{GPa}$ using the Oliver-Pharr method [30]. The nanohardness measurement of individual polygonal grains was determined by looking into the optical microscope attachment provided with the nanoindenter so as not to include the hardness of phase boundary. It is known that the hardness of the ferrite grains depends upon carbon content, density of dislocations, and precipitation. In present study, the specimens were isothermal held, so the carbon content should be close to the equilibrium concentration and with ferrite grains of similar dislocation density. Thus, the difference in nanohardness should be determined by the density of the precipitated carbides in the polygonal ferrite. Meanwhile, there was less variation in hardness for the specimens isothermally treated at $650{ }^{\circ} \mathrm{C}$, implying that the carbides in the specimens isothermal treated at $650{ }^{\circ} \mathrm{C}$ were more uniformly dispersed and the number density of the carbides was greater than that treated at $600{ }^{\circ} \mathrm{C}$. This method is also used in Refs. [26] and [31].

Figure 13a shows BF image of interphase precipitation, and the HRTEM image of the circled precipitate is displaced in Fig. 13b. The crystal structure and the orientation relationship were identified by fast Fourier transformed (FFT) diffractogram, as illustrated in Fig. 13c. It can be concluded that the carbides had a NaCl-type crystal structure and the three carbides in Fig. 13b exhibited the same variant of the Baker-Nutting (BN) orientation relationship with the ferrite matrix. Smith and Duune have proposed a convincing explanation about there is only one 

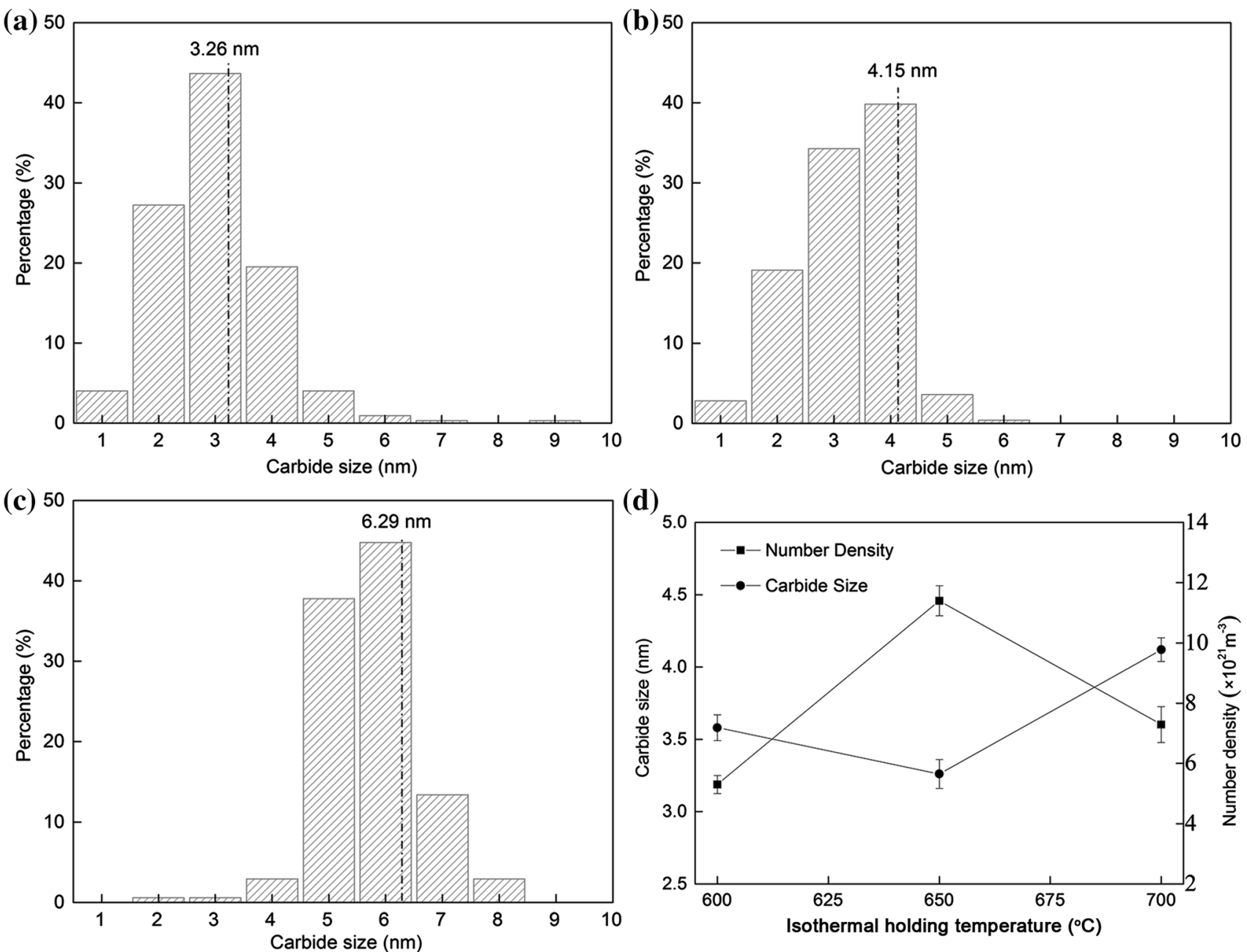

Fig. 11 Size distribution histograms of nanoscale precipitates in the specimens with different isothermal holding times of a 10, b 20 , c 60 min at $650{ }^{\circ} \mathrm{C}$, d plots showing variation of precipitation size and fraction as a function of isothermal holding time
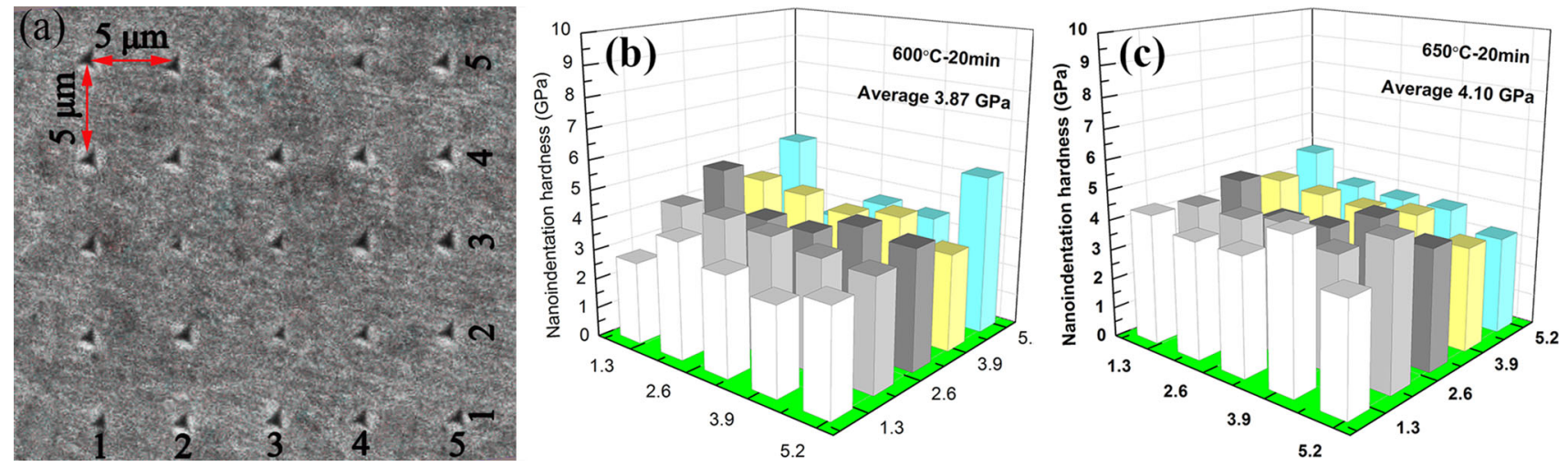

Fig. 12 a Typical indentation morphology by nanoindenter, hardness distribution of the specimens isothermally treated at b $600{ }^{\circ} \mathrm{C}, \mathbf{c} 650{ }^{\circ} \mathrm{C}$ for $20 \mathrm{~min}$

variant of the $\mathrm{BN}$ orientation relationship between interphase precipitation carbides [32]. The preferred variant can maintain the smallest angle between the interface of ferrite and the carbide broad of the carbides, and it is preferable to other variants during the interphase precipitation. 

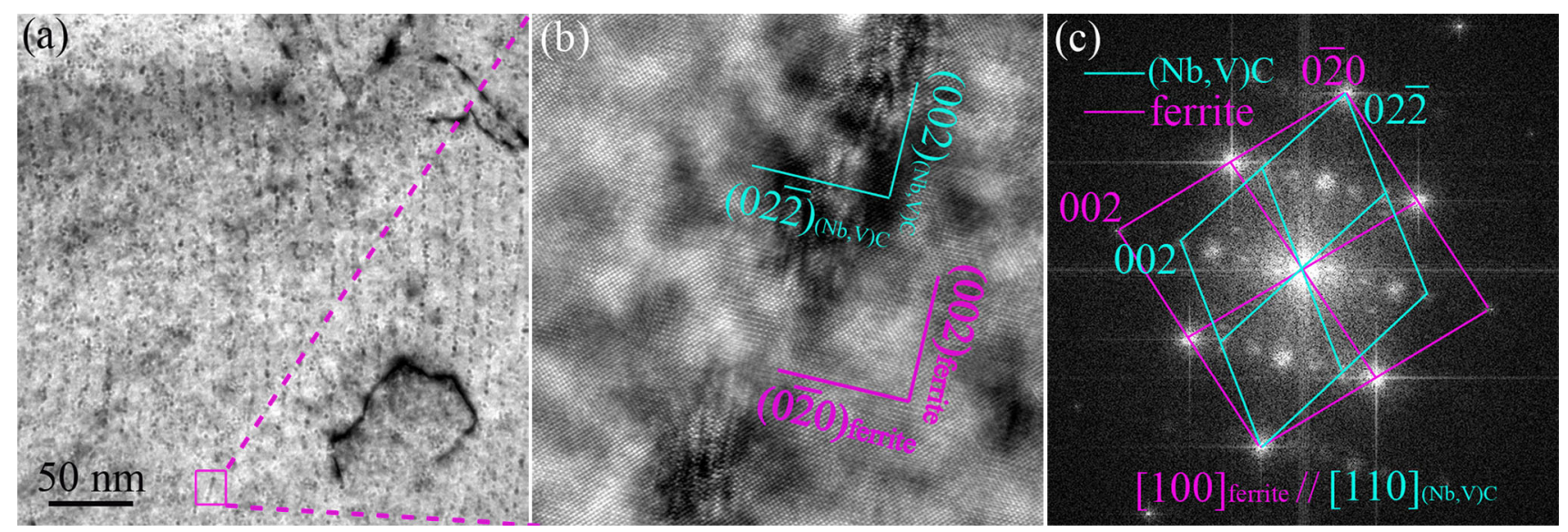

Fig. 13 a TEM image of interphase precipitation, b HRTEM image of the interphase precipitation and the corresponding FFT diffractograms of nanocarbides obtained from the specimen isothermally treated at $700{ }^{\circ} \mathrm{C}$ for $60 \mathrm{~min}$

\subsection{Precipitation Strengthening}

To estimate precipitation strengthening, both types of precipitation (interphase precipitation and random precipitation) need to be considered. As regards, randomly distributed precipitate strengthening, the contribution to yield strength was estimated by Ashby-Orowan [33, 34]:

$\Delta \sigma_{\text {ran }}=10.8 \sqrt{ } f / d \ln (1630 d)$

Where, $\Delta \sigma_{\text {ran }}$ represents the random precipitation strengthening increment in $\mathrm{MPa}, f$ is the volume fraction of random distributed carbides and $d$ is the diameter of carbide in $\mu \mathrm{m}$. This model was previously shown to provide a reasonable and quantitative estimate of randomly distributed precipitation strengthening of fine carbides observed in microalloyed steels. $\Delta \sigma_{\mathrm{ran}}$ of specimens isothermally treated at $650{ }^{\circ} \mathrm{C}$ for 10,20 and 60 min was calculated to be 79.6, 109.7 and 104.2 MPa, respectively, in specimens isothermally treated at 600 and $700{ }^{\circ} \mathrm{C}$ for 10 min was 60.0 and $81.6 \mathrm{MPa}$ and in specimens isothermally treated at $700{ }^{\circ} \mathrm{C}$ for $60 \mathrm{~min}$, it is $71.3 \mathrm{MPa}$. With regard to interphase precipitation, the contribution to yield strength due to the Orowan mechanism is given by:

$\Delta \sigma_{\text {inter }}=M G b / \sqrt{ } r_{1} r_{2}$

Where $M$ is the Taylor factor, $G$ is the shear modulus, $b$ is the magnitude of Burgers vector, and $\sqrt{ } r_{1} r_{2}$ means the mean intercarbide spacing in the slip plane. For ferritic steel, $M$ is $2.75, G$ is $80300 \mathrm{MPa}$ [33], $b$ is $0.248 \mathrm{~nm}$ and $r_{1}$ , $r_{2}$ can be estimated from the following equation:

$r_{1}=\omega^{2} / \omega_{0}$

$r_{2}=s / \sin \varphi$

where $r_{1}$ is the mean linear intercarbide spacing along the intersection between the slip plane and the sheet plane, $\omega$ is the average intercarbide spacing in the sheet plane, $\omega_{0}$ is the mean projected value of the intercarbide spacing in sheet, $r_{2}$ is the mean projected value of the perpendicular sheet spacing, $s$ is the perpendicular sheet spacing, and $\varphi$ is the angle between sheet plane normal and slip plane normal, as shown in the schematic diagram in Fig. 14. The multiple slip systems in ferrite lead to complexity in determining the value of $\varphi$. The sheet plane is oriented close to $(013)_{\alpha}$ as shown in Fig. 6(a), and the possible slip planes can be $\{110\}_{\alpha},\{112\}_{\alpha}$ and $\{123\}_{\alpha}$. According to Equation (9), a lower $\varphi$ will bring about a larger $r_{2}$, and thereby the dislocations on this slip plane are much easier to bow out between carbides. Therefore, the data with the lowest $\varphi$ needs to be taken into account to estimate the yield stress and the corresponding values of $1 / \sin \varphi$ are listed in Table 1 . The general average value of $1 / \sin \varphi$ was determined to be 2.43 in our study and $r_{1}$ and $r_{2}$ were determined to be 720 and $46.17 \mathrm{~nm}$. The contribution of

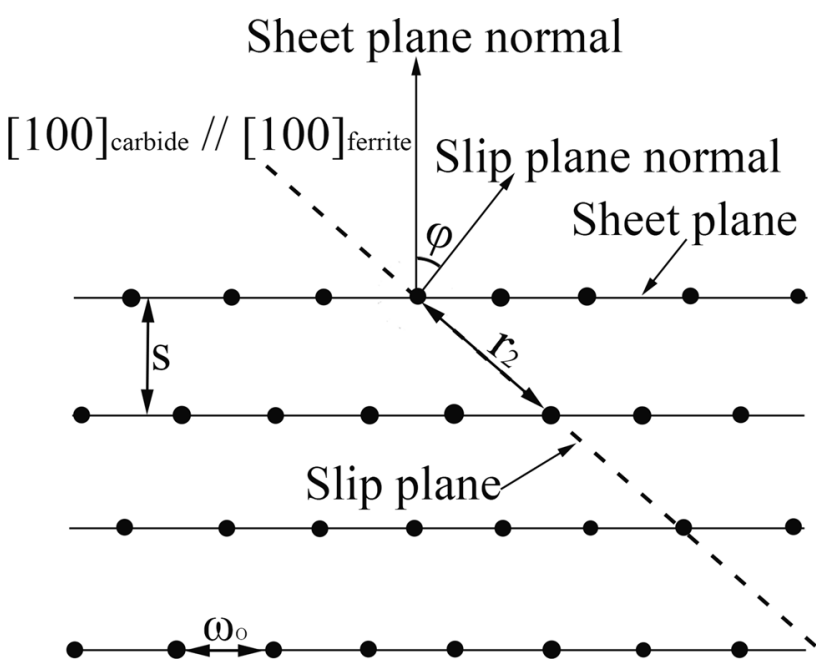

Fig. 14 Schematic diagram showing the determination method of intercarbide spacing in slip plane 
Table 1 Value of $1 / \sin \varphi$ obtained from the lowest $\varphi$ for (013) plane

\begin{tabular}{lll}
\hline $\begin{array}{l}\text { Sheet } \\
\text { plane }\end{array}$ & $\begin{array}{l}1 / \sin \varphi \text { (multiplication: slip } \\
\text { plane) }\end{array}$ & $\begin{array}{l}\text { Average value } \\
\text { of } 1 / \sin \varphi\end{array}$ \\
\hline$(013)$ & $2.236(1:(011))$ & $2.429 \pm 0.286$ \\
& $2.335(2:(112)$ and $(\overline{1} 12))$ & \\
& $2.715(2:(123)$ and $(\overline{1} 23))$ & \\
\hline
\end{tabular}

interphase precipitation in specimen isothermally treated at $700{ }^{\circ} \mathrm{C}$ for 60 min was estimated to be $300.36 \mathrm{MPa}$ using this method. In this specimen, both interphase precipitation and random precipitation was observed, but the interphase precipitation occurred in three ferrite grains among the thirty ferrite grains observed. The total yield precipitation strengthening was estimated using equation (10):

$\Delta \sigma_{\text {total }}=N_{\text {inter } \times} \Delta \sigma_{\text {inter }}+\left(1-N_{\text {inter }}\right) \times \Delta \sigma_{\text {ran }}$

Where, $N_{\text {inter }}$ is the percentage of ferrite grains with interphase precipitation in total observed grains. The yield strength of the specimen isothermally treated at $700{ }^{\circ} \mathrm{C} 60$ min was $\sim 94.2 \mathrm{MPa}$. Compared all specimens, the contribution of precipitation strengthening to yield strength was maximum at $\sim 109.7 \mathrm{MPa}$ with holding time of $20 \mathrm{~min}$ at $650{ }^{\circ} \mathrm{C}$.

\section{Conclusions}

The precipitation behavior of high-strength $\mathrm{Nb}-\mathrm{V}$-microalloyed steels subjected to different isothermal holding temperatures and time was studied by TEM. The important findings of the study were as follows:

1. The microstructure primarily consisted of the ferrite and martensite. The volume fraction of the ferrite phase decreased with the increase in the isothermal temperature for equilibrium content of ferrite fraction at various temperatures, and the ferrite grain size increased with rising in the isothermal temperature because of reduced nucleation at high temperatures.

2. Besides randomly distributed precipitates, interphase precipitates were also observed in the specimens isothermally treated at $700{ }^{\circ} \mathrm{C}$ for $60 \mathrm{~min}$. While the specimens isothermally heat-treated at 650 and $600{ }^{\circ} \mathrm{C}$ for 10,20 , and $60 \mathrm{~min}$ and $700{ }^{\circ} \mathrm{C}$ for 10 and $20 \mathrm{~min}$, only random precipitation was observed. It may be noted that interphase precipitation just nucleated in the specimens isothermally treated at high temperatures and long time, and this can be explained by mass balance criterion during the diffusional phase transformation process.

3. The contribution of precipitation strengthening to yield strength calculated using Ashby-Orowan model approached to a maximum of $\sim 110 \mathrm{MPa}$ at the isothermal temperature of $650{ }^{\circ} \mathrm{C}$ for $20 \mathrm{~min}$.

Acknowledgements The research was supported financially by National Science Foundation of China (Grant Nos. 51234002, 51504064, and 51474064), National Key Research and Development Program 2016YFB0300601, China Postdoctoral Science Foundation 2016M591443, and the Fundamental Research Funds for the Central Universities N160704002, N160708001. The China Scholarship Council is also acknowledged sincerely for supporting us to complete this work.

\section{References}

[1] Y. Funakawa, T. Shiozaki, K. Tomita, T. Yamamoto, E. Maeda, ISIJ Int. 44, 1945 (2004)

[2] B. Wang, Z.D. Wang, B.X. Wang, G.D. Wang, R.D.K. Misra, Metall. Mater. Trans. A 46, 2834 (2015)

[3] K. Nishioka, K. Ichikawa, Sci. Technol. Adv. Mater. 13, 1 (2012)

[4] E. Abbasi, W.M. Rainforth, J. Mater. Sci. Technol. 33, 311 (2017)

[5] F.Q. Ji, C.N. Li, S. Tang, G. Yuan, G.D. Wang, ISIJ Int. 56, 602 (2016)

[6] S. Tang, Z.Y. Liu, G.D. Wang, R.D.K. Misra, Mater. Sci. Eng. A 580, 257 (2013)

[7] K. Zhang, Z.D. Li, X.J. Sun, Q.L. Yong, J.W. Yang, Y.M. Li, P.L. Zhao, Acta Metall. Sin. (Engl. Lett.) 28(5), 641 (2015)

[8] G.K. Tirumalasetty, C.M. Fang, Q. Xu, J. Jansen, J. Sietsma, M.A. van Huis, H.W. Zandbergen, Acta Mater. 60(20), 7160 (2012)

[9] Y. Han, J. Shi, L. Xu, W.Q. Cao, H. Dong, Mater. Sci. Eng. A 553, 192 (2012)

[10] H.W. Yen, P.Y. Chen, C.Y. Huang, J.R. Yang, Acta Mater. 59, $6264(2011)$

[11] M.Y. Chen, M. Gouné, M. Verdier, Y. Bréchet, J.R. Yang, Acta Mater. 64, 78 (2014)

[12] J. Chen, M.Y. Lv, S. Tang, Z.Y. Liu, G.D. Wang, Mater. Sci. Eng. A 594, 389 (2014)

[13] H.J. Kestenbach, E.V. Morales, Acta Microscopica 7(22), 22-33 (1998)

[14] W. Saikaly, L. Charrin, A. Charaï, X. Bano, C. Issartel, Metall. Mater. Trans. A 32, 1939 (2001)

[15] X.Y. Huang, The Microstructure of Materials and its Electron Mircroscopy Analysis (Metallurgical Industry Press, Beijing, 2008)

[16] Y. Han, J. Shi, L. Xu, W.Q. Cao, H. Dong, Mater. Design 34, 427 (2012)

[17] A.D. Batte, R.W.K. Honeycombe, Met. Sci. J. 7, 160 (1973)

[18] H.W. Yen, C.Y. Huang, J.R. Yang, Scr. Mater. 61, 616 (2009)

[19] R. Okamoto, A. Borgenstam, J. Ågren, Acta Mater. 58, 4783 (2010)

[20] F.Z. Bu, X.M. Wang, L. Chen, S.W. Yang, C.J. Shang, R.D.K. Misra, Mater. Charact. 102, 146 (2015)

[21] F.Z. Bu, X.M. Wang, S.W. Yang, C.J. Shang, R.D.K. Misra, Mater. Sci. Eng. A 620, 22 (2015)

[22] S.S. Campos, E.V. Morales, H.J. Kestenbach, Mater. Charact. 52, 379 (2004)

[23] R.W.K. Honeycombe, Metall. Mater. Trans. A 7, 915 (1976)

[24] D.A. Porter, K.E. Easterling, Phase Transformation in Metals and Alloys, 2nd edn. (Chapman \& Hall, 1991)

[25] C.Y. Chen, C.C. Chen, J.R. Yang, Mater. Sci. Eng. A 626, 74 (2015) 
[26] X.L. Li, Z.D. Wang, X.T. Deng, G.D. Wang, R.D.K. Misra, Metall. Mater. Trans. A 47, 1929 (2016)

[27] J.B. Wiskel, D.G. Ivey, H. Henein, Metall. Mater. Trans. B 39, 116 (2007)

[28] S. Mukherjee, I.B. Timokhina, C. Zhu, S.P. Ringer, P.D. Hodgson, Acta Mater. 61, 2521 (2013)

[29] K.L. Johnson, (Cambridge University Press, Cambridge, 1985)
[30] W.C. Oliver, G.M. Pharr, J. Mater. Res. 7, 1654 (1992)

[31] Y. Xu, W.N. Zhang, M.X. Sun, H.L. Yi, Z.Y. Liu, Mater. Lett. 139, 177 (2015)

[32] R.M. Smith, D.P. Dunne, Mater. Forum 11, 166 (1988)

[33] T. Gladman, The Physical Metallurgy of Microalloyed Steels (The Institute of Materials, London, 1997)

[34] H.J. Kestenbach, J. Gallego, Scr. Mater. 44, 791 (2001) 